\section{Lymarenko $\mathbf{Y}$,} Tatievskyi $\mathbf{D}$.

\title{
RECOGNIZING WHEELS WITH A LASER TO CALCULATE THE DEFORMATION OF TIRES
}

В ході досліджень реалізовано алгоритм розпізнавання променя лазера в області колеса транспортного засобу, що, безсумнівно, має самостійну иінність. Отримано мінімізовану кількість пікселів в ROI (область колеса) для подальшого відновлення 3D-моделі коліс. За такої моделі здійснені обчислення коефіцієнтів деформачії коліс транспортного засобу.

Ключові слова: Детектор ребер Канні, диференщійний оператор Собеля, комп'ютерний зір, медіанний фільтр, перетворення Хафа.

\section{Introduction}

Computer vision is one of the most modern areas that use the results of many related scientific areas, such as machine learning, projective geometry, probability theory, etc.

The main circle of computer vision tasks lies in the sphere of qualitative and quantitative analysis of images and video data streams (search and classification of objects, support of objects on video, etc.). Image recognition is a complex task for a computer algorithm. This is due, first of all, to the high variability of images of individual objects [1-3].

Most methods for solving these problems, in one way or another, use different approaches to perform preprocessing of images or frames of the video stream, with the aim of further improving the quality of the algorithms. Different algorithms have their advantages and disadvantages, as a consequence, all algorithms have their own scope. In this study, the recognition of the wheels of a vehicle is realized by their illumination with a laser beam. The relevance of such recognition is associated with many practical applications for analyzing their condition, in particular, determining the deformation of the tires, which was done during the research. From the physical and mechanical properties of the tire depends on the performance of the car, such as load capacity, economy, handling, patency, etc. Ultimately, all these indicators are determined by the value and type of deformation of the tire, under the influence of external forces.

\section{The object of research and its technological audit}

The object of research is a system for recognizing wheels using a laser to calculate the deformation of tires.

The main problem of this research, for the solution of which it is necessary to recognize the wheels of a vehicle with the help of laser illumination, with the subsequent restoration of their three-dimensional surfaces is the calculation of the deformation coefficient of the vehicle wheels.

The application for the study is implemented in the C\#-programming language in the Microsoft Visual Studio 2017 environment, using the EmguCV library (OpenCV for .NET). This library is very popular due to its openness and the ability to use it for free for educational and commercial purposes. At the moment, working with the OpenCV library is well documented, there are many examples and practical tips [4-6], the following greatly speeds up the process of software implementation.

The practical value of this study is that its results can be applied in real conditions, which require the presence of an infrared camera, a laser, and radar that determines the speed of the vehicle. The obtained results can be integrated with the TPMS (Tire Pressure Monitoring System) information to determine the load of vehicles.

\section{The aim and objectives of research}

The aim of research is solution of the problem of restoring three-dimensional surfaces of the vehicle wheels, with the subsequent solution of the problem of calculating the coefficients of their deformation.

To achieve this aim, it is necessary to solve the following tasks:

1. To consider the components for building an algorithm for restoring three-dimensional surfaces used in computer vision.

2. To recognize the wheels using a laser to calculate the deformation of the tires.

\section{Research of existing solutions of the problem}

One of the most common tasks of computer vision is the classification problem. In the framework of this task it is required to determine whether a certain image, or part of it, belongs to a certain class. An example of such task is the task of automatic search and localization of objects [7-11], including, vehicle wheels, on an image or in a video stream.

A similar problem is solved using various algorithms used in computer vision [12-14].

The method of Viola-Jones has huge advantages in the speed of recognition of machines in the image, but the shortcomings of this algorithm are the long training time of the classifier and the impossibility of recognizing machines with an angle of inclination greater than 30 degrees. It is possible also to say that this method is one of the best in terms of the ratio of the recognition efficiency and the speed of work [15]. 
As shown by the analysis, the image of the vehicle wheels do not contain a sufficient number of stable contrast areas of a predetermined size. It would seem that the center of the image of the wheel should be lighter than the tires, but this is not always the case. The same with the background - asphalt can be as darker than tires, and lighter than them. This situation is determined not only by different types of wheels, car bodies, but also by the conditions of illumination. The image of the same wheel can drastically change when the lighting conditions change.

The signs of the digital image used in pattern recognition are the Haar-like features. Their name is due to an intuitive resemblance to the Haar wavelets. The Haarlike features give the value of the brightness difference between the dark and light part of the sign. For example, in the following images, the value of the characteristic will be positive, since the areas of the light part of the sign are lighter than the dark part, and, therefore, the black A-region is larger than the B-region of white color.

The Viola-Jones classifier, using the Haar-like features constructed from a luminous image, is sensitive to the characteristic brightness differences when one part of the image is always darker than the other.

Due to these circumstances, Canny detector, the contour analysis, the SURF method and others, used at the initial stages of the solution of the task in view, are unsatisfactory to solve the problem of the most accurate recognition of the wheels. Attempts were made to calculate the deformation coefficient of the wheels from the image obtained with the help of a video camera, however, for the reasons mentioned above, such approach did not provide the necessary accuracy.

Therefore, during the research, the idea of using laser illumination of a wheel was adopted with the subsequent reconstruction of its three-dimensional model, which was realized earlier [16].

It is this approach that made it possible to provide the necessary accuracy in calculating the deformation coefficient.

\section{Methods of research}

The methods of theoretical (abstraction, analysis and synthesis) and empirical research were used in the work.

The empirical study consisted in observing the quality of laser beam detection on the image, which allowed choosing the optimal parameters for the used library methods, described below.

An important place in the methodology of the study was the method of generalizing scientific literature, the list of which is attached, especially in the context of using the OpenCV library tools, which greatly accelerated the software implementation of the application.

The methods applied corresponded to the logic of the study and were complex interrelated.

It is also note that by modeling real processes with the required accuracy, the approach under investigation does not require the availability of expensive equipment. In the study, a vertical laser and a camera were used to recognize the wheels in real conditions.

\section{Research results}

In the Unity 3D system, the original model of the vehicle is developed, with the possibility of its illumina- tion by a laser beam of various colors during the motion, depicted in Fig. 1. The model corresponds to the KamAZ-53215 vehicle, the wheels are made separately in accordance with this car.

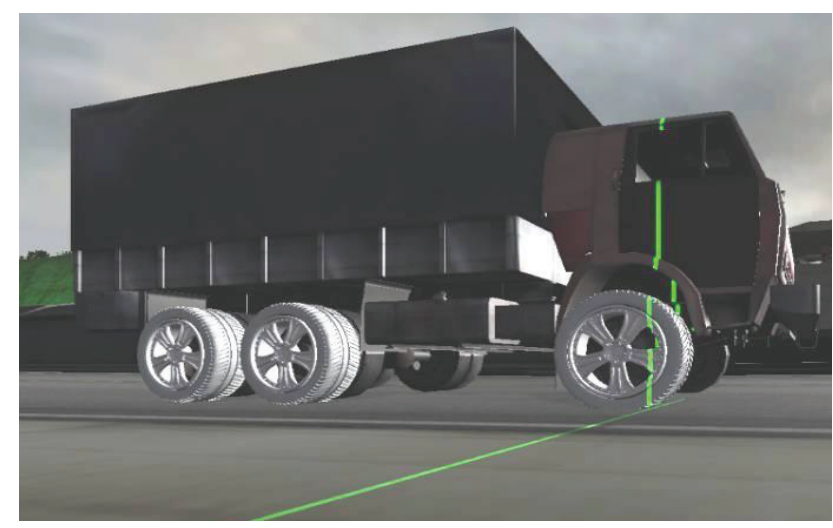

Fig. 1. Model of the vehicle in Unity $3 D$

In the same system, a set of images of this process is obtained at regular intervals in the form of graphic files for their processing with the $\mathrm{C} \#$-application. At the same time, the application has a mode for visualizing the laser beam detection process in ROI with the selected color and in real time. The result of this processing is the generation of two-dimensional coordinates of the laser beam in the region of the vehicle wheels.

Due to the fact that only a vertical ray of a certain color is supposed to be detected (red, green), vertical lines are detected using the OpenCV library, using the HoughTransform transformation, a method for finding lines (circles and other simple forms) in an image [16]. This is preceded by a standard preprocessing of the image with sequential use of smoothing/blurring, by calculating a convolution of an image with a discrete Gauss core, with standard deviations in the $O x$ and $O y$ axes, respectively [17], and blurring by applying a median filter.

After performing filtering operations, Sobel operator, a discrete differential operator, is used to calculate the approximate values of derivatives of different orders for the pixel brightness function [17].

The use of the horizontal Sobel operator makes it possible to clearly distinguish vertical edges (the first partial derivative along the $O x$ axis is applied).

Next, the Canny edge detector [18] is used to find the boundaries of objects in the image. On the found faces, the construction of Hough segments (HoughLinesP library function) is performed to obtain the required set of pixels for restoring the three-dimensional image of all vehicle wheels.

It should be noted that the efficiency of using the functions described above from the OpenCV library, to a large extent, depends on empirically selected parameters, and for this purpose a number of experiments are performed on their optimal choice.

In the course of such experiments, it is possible to detect the maximum number of Hough segments in the ROI (actually, the wheel region).

At the same time, the possibility of using both red and green lasers is taken into account. The fragment of the application for determining the Hough lines (yellow segments) on the trajectory of the green laser beam in the ROI is shown in Fig. 2. 


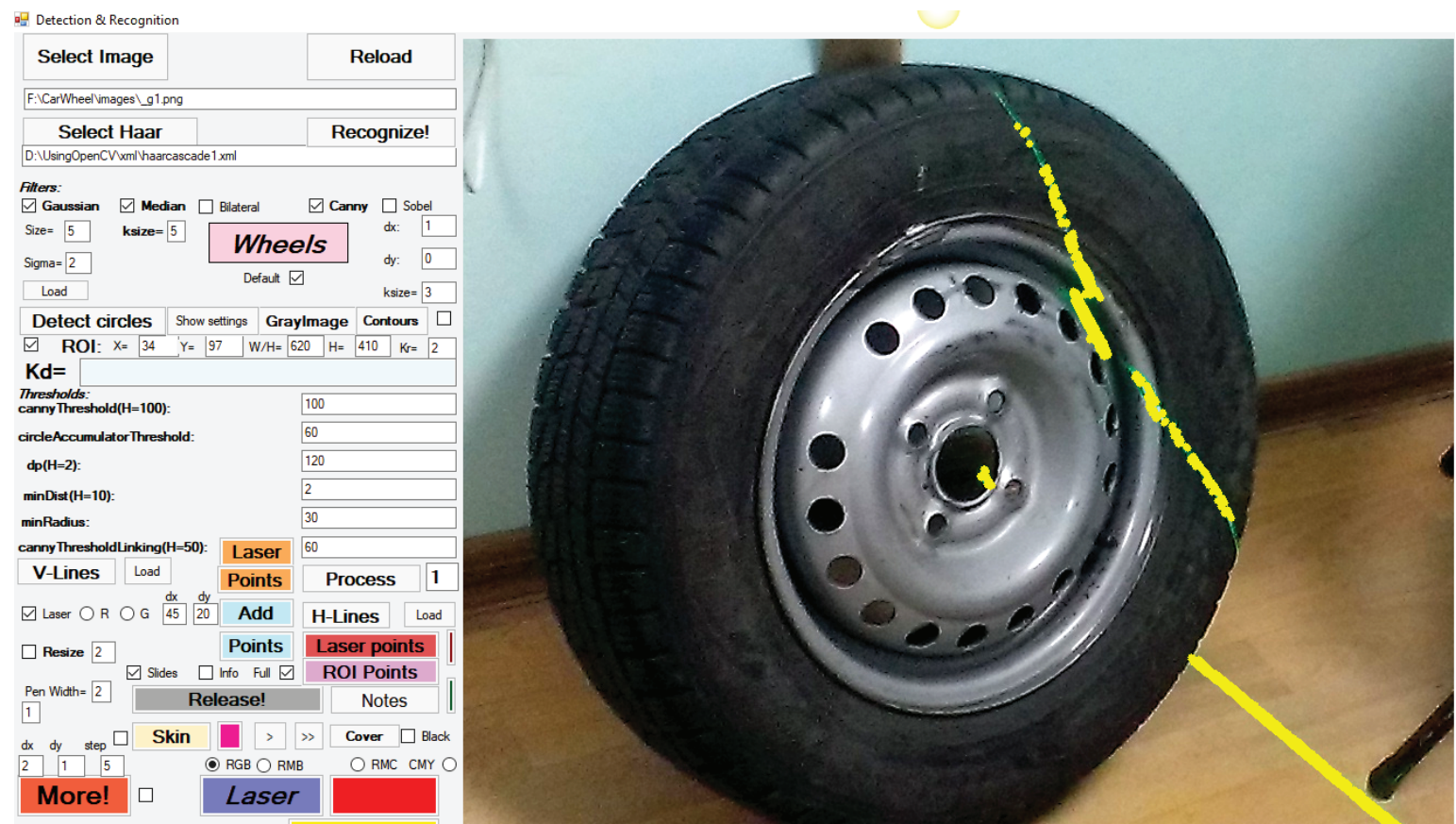

Fig. 2. Determination of Hough segments on the laser trajectory

Let's note that the application has processed the actual image from the video camera. The process of such preprocessing of images can be illustrated by the following block diagram (Fig. 3).

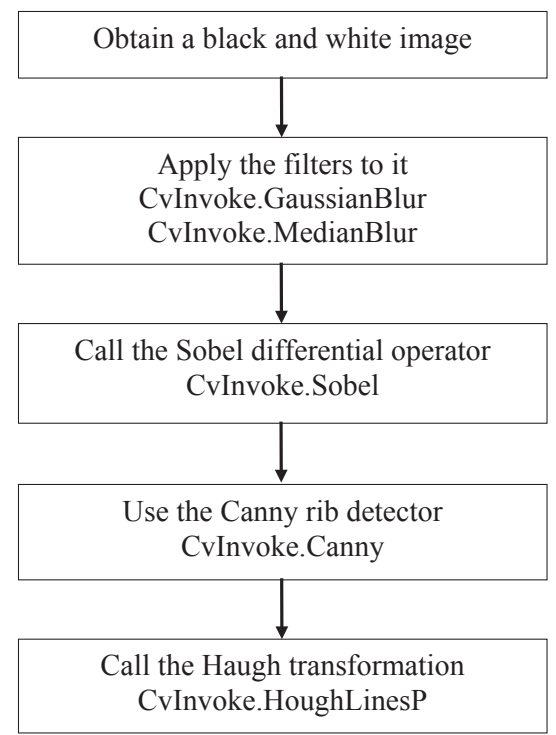

Fig. 3. Preprocessing of images

However, with such a detection of the lines on the laser beam trajectory, it is not possible to obtain a continuous linear spline. The image processing is implemented by a separate application method, which calculates the missing segments of the spline with their verification that the laser beam is in color (for red and green lasers) and spatial ranges.

All Hough segments recognized in this manner on the source image are highlighted with a certain «pure» color (for example, red), to improve the accuracy of further image processing.
In the course of the study, all the obtained lines were pixel-by-pixel covered with dots. Thus, the principal problem of finding the points belonging to the laser beam is solved.

Then the problem of minimizing the points on the ray in ROI is solved. Fig. 4 shows their complete set.

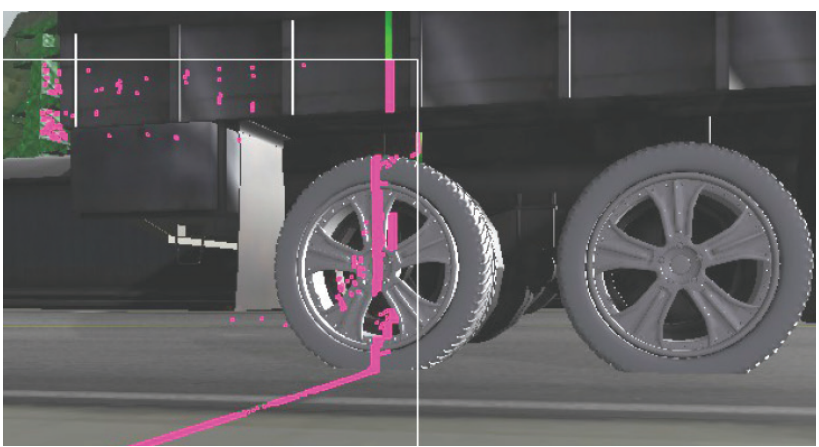

Fig. 4. Detection of all points on the laser beam

them on the laser beam within the ROI, also to remove the garbage left after the color detection. This task is solved by additional methods called sequentially over an existing list of points (pixels) that take it as a parameter and return the updated list. To handle such collections, lambda expressions are used for sorting, filtering, searching for extreme values, and so on.

Thus, the garbage is cleaned, the top and bottom points are deleted outside the ROI and minimized - left only the pixel on the ray for each level $y=$ const.

The result of the sequence of such actions leads to the complete identification of laser dots only in the wheel region on the entire set of images, as seen in Fig. 5.

The entire process of processing a set of images of the vehicle is presented in the block diagram in Fig. 6, where the set of operators «Preprocessing images» corresponds to the flowchart (Fig. 3). 


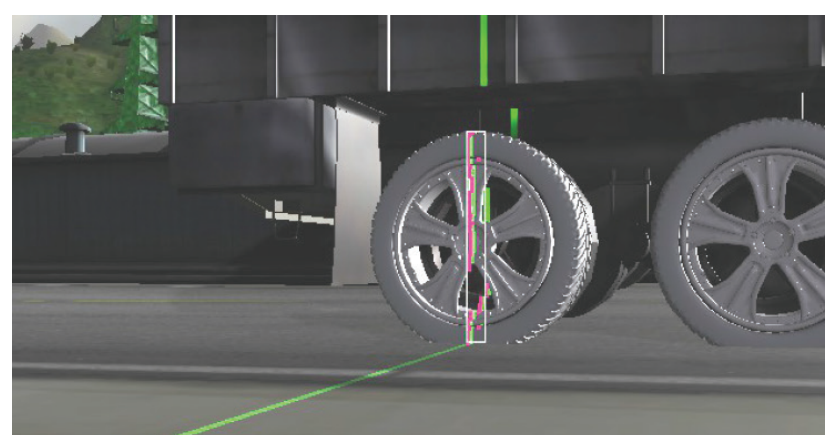

Fig. 5. Minimization of the points on the laser beam

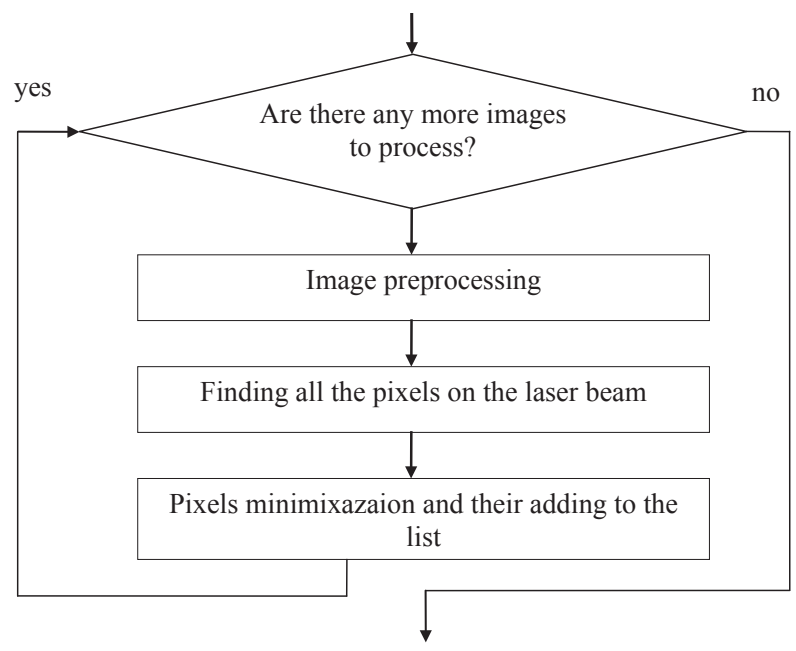

Fig. 6. Full cycle of image processing

The resulting set of points of the entire vehicle traffic session was recorded in a CSV file, which was used to restore the three-dimensional image of the wheels according to the previously implemented algorithm [16].

To calculate the coefficient that takes into account the tire deformation when a vertical load is applied to it, information is used in the form of a three-dimensional cloud of points, the visualization of which in the MeshLab system is shown in Fig. 7.

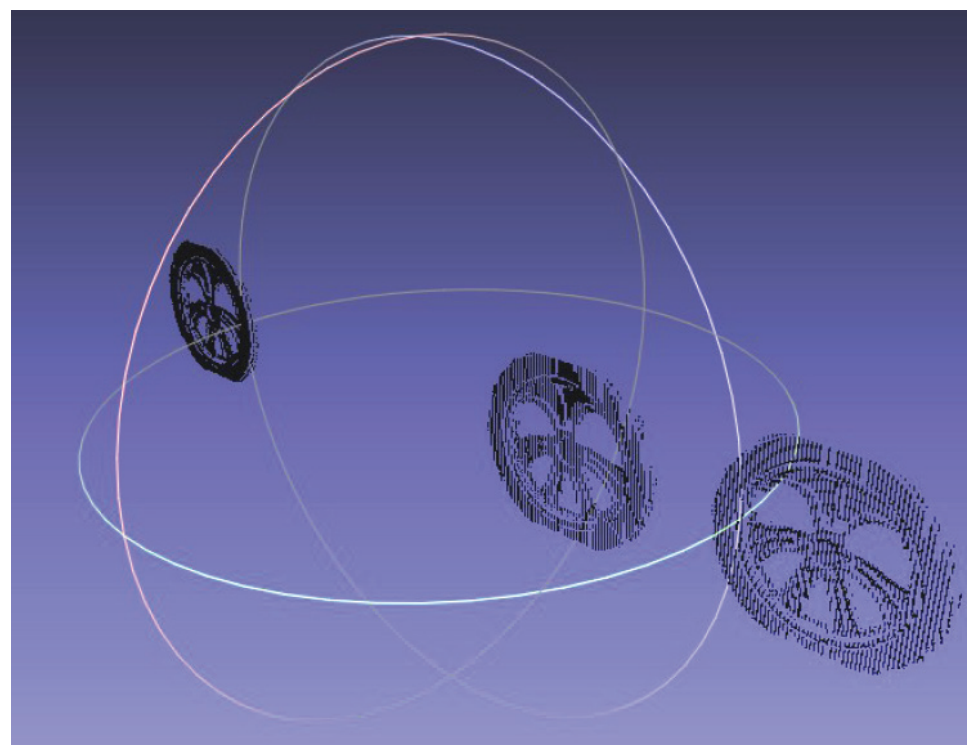

Fig. 7. Visualization of a cloud of points in the MeshLab system
Let's note that the radial deformation of the tire is measured by its normal deflection equal to the difference between the free $(R 0)$ and static $(R s t)$ wheel radii:

$$
H n=R 0-R s t \text {, }
$$

where $R 0$ - the free wheel radius; $R s t$ - the static radius of the wheel.

The free radius is the radius of the wheel in a free (not loaded) state.

Under the influence of a static vertical load (the weight of a stationary machine), as a result of deformation of the elastic structure of the tire, the distance from the wheel axis to the support surface decreases. This distance is called the static radius of the wheel:

$$
R s t=R 0(1-\lambda)
$$

where $\lambda-$ a coefficient that takes into account the tire deformation when a vertical load is applied to it, which is calculated in the appendix.

Such calculation is performed by a separate method of a special application class, which returns the value of the deformation coefficient for the detected wheel.

The list of points of the input file is passed to the constructor of this class. The method determines the coordinates of the «critical» points needed for further calculations. This, in fact, points with the minimum and maximum values of $x$ and $y$ coordinates. In this case, the point with the minimum $x$-coordinate is chosen with the minimum coordinate $z$ and vice versa, which is necessary for a more accurate determination of the radius of the wheel. Calculation of the entire set of deformation coefficients (over all wheels) is performed cyclically.

A fragment of the developed application with calculated deformation coefficients for all three wheels is shown in Fig. 8.

It should be noted that in the above method, the ratio of the distance from the point with the minimum $y$-coordinate to the center of the wheel (circle) to the radius of the wheel is calculated, the latter being calculated taking into account the $z$-coordinates of its extreme points.

Thus, the numerator is the static radius of the wheel, the denominator is the free radius. The obtained value is subtracted from unity and equal to the coefficient $\lambda$. For the point cloud of the model in use, it is within 0.1 , which corresponds to the norm for trucks, according to UNECE Regulations No. 30.

As a result of the carried out researches the set task on calculation of the coefficient of deformation of tires (wheels) of a vehicle is solved. The simulation allows to approximate the model of the vehicle to the real conditions and to obtain the values of these coefficients, corresponding to the norms for trucks.

It should be noted that in addition to this result, the achievement of which is the purpose of the study, it is possible to restore the vehicle wheels three-dimensional.

Such opportunity is of practical interest for a thorough and comprehensive study of the condition of the tires and, in general, the vehicle wheels. 


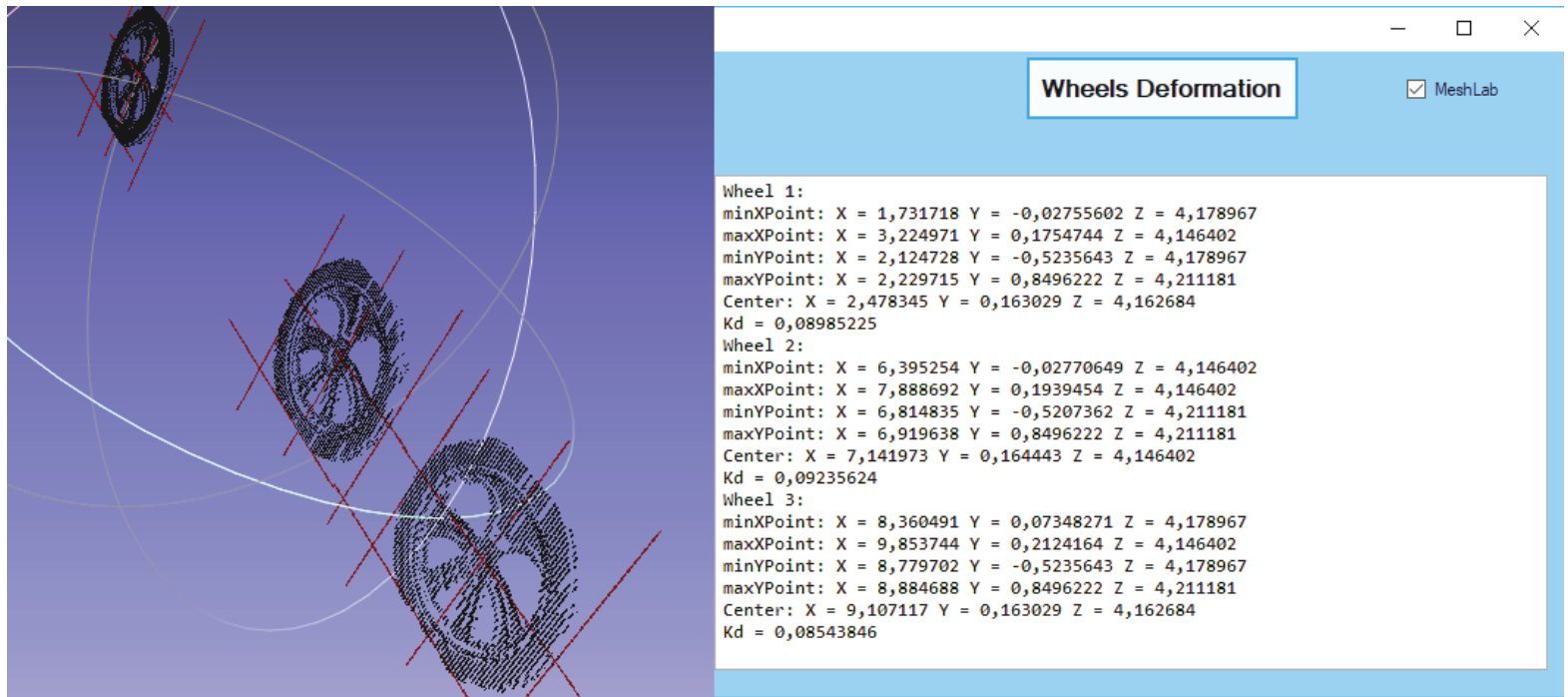

Fig. 8. Calculation of the deformation coefficients

\section{SWOT analysis of research results}

Strengths. The implemented method for determining the recognition of vehicle wheels by their illumination with a laser beam of deformation of tires allows this operation to be performed with a high certainty degree. The very same method of recognition using laser illumination is of independent value and can be applied to any objects. The results of deformation calculation can be integrated with the information of the tire pressure monitoring system, which increases the practical value of the carried out studies. Undoubted advantages of this approach include relatively low cost of equipment consisting of household appliances.

Weaknesses. The weaknesses of this approach include the fact that in practice it is not always possible to obtain an acceptable quality result associated with possible dusty roads and unfavorable weather conditions. However, as the experiment showed, recognition quality improvement is achievable through improved software.

Opportunities. At the moment, it is quite possible to use this method in practice, both for direct calculation of deformations, and for solving more complex problems by integration with the TPMS (Tire Pressure Monitoring System).

Threats. At present, analogues of the use of this model have not been found in practice, and the developed method does not cause any special problems for its practical application.

\section{Conclusions}

1. A review is made for the existing complexes of theoretical and empirical methods, the combination of which makes it possible to study the object under study with the greatest certainty by using laser illumination of a wheel, followed by the reconstruction of a three-dimensional model. The implemented algorithm for recognizing the laser beam in the region of the vehicle wheel is of independent value, since it can be used to detect any objects using a vertical or horizontal laser of different colors. In the developed application there is a choice of red and green laser. Multiple pixels in the ROI are obtained and minimized to further restore the 3D model of the wheels. This algorithm, based on a sequential method call using lambda expressions, also has a universal character, and is applicable to any objects.

2. During the research on the obtained model, the coefficients of wheel deformation are calculated. This indicator characterizes the relative change in the main geometric dimensions of the processed image (length, width, height) during deformation. The resulting values of these coefficients, according to UNECE Regulations No. 30, are in line with the standards for trucks.

In real conditions, the following algorithm could be applied: near, for example, an infrared camera and a laser, as well as radar that determines the speed of the vehicle, which will pass through the checkpoint and be photographed by the camera $n$ times. Knowing the speed and time of the picture, it is possible to accurately determine the displacement of the car from the beginning of tracking. From each received image, it is possible to calculate a set of $3 \mathrm{D}$ points by shifting them along the $X$ axis to the offset value of the car, and add them to the common set. From the received set of points it is possible to choose wheels and define deformation of tires, as it was done, using computer modeling.

The practical value of this research is also that for the determination of the loading of vehicles, it is of interest to integrate the obtained results with the information of the tire pressure monitoring system - TPMS.

\section{Acknowledgements}

The work is carried out within the framework of the comprehensive research topic of the Zaporizhzhia National Technical University «Development of modern methods of computer modeling» (state registration number 25-1DB/04) with the support of the Software Engineering Department of the Zaporizhzhia State Engineering Academy (Ukraine).

\section{References}

1. Sonka M., Hlavac V., Boyler R. Image Processing, Analysis, and Machine Vision. Stamford: Cengage Learning, 2014 URL: https://www.researchgate.net/profile/Roger_Boyle/publication/220695728_Image_processing_analysis_and_and_machine_vision_3_ed/links/5553203108ae980ca606d93c/Imageprocessing-analysis-and-and-machine-vision-3-ed.pdf 
2. Szeliski R. Computer Vision Algorithms and Applications. London: Springer-Verlag, 2010. URL: http://szeliski.org/Book/ drafts/SzeliskiBook_20100903_draft.pdf

3. Wang J., Cohen M. F. Image and Video Matting: A Survey // Foundations and Trends in Computer Graphics and Vision. 2007. Vol. 3, No. 2. P. 97-175. doi:10.1561/0600000019

4. OpenCV 2.4.13.4 documentation. 2017. URL: https://docs opencv.org/2.4/doc/tutorials/imgproc/imgtrans/hough_lines/ hough lines.html

5. Zeeshan A. A. A Quick Introduction To Computer Vision Using C\#. 2016. URL: http://www.c-sharpcorner.com/article/ a-quick-introduction-to-computer-vision-using-c-sharp

6. Bradski G., Kaehler A. Learning OpenCV: Computer Vision with the OpenCV Library. O'Reilly Media, 2008. P. 580.

7. Christoudias C. M., Georgescu B., Meer P. Synergism in low level vision // Proceedings of 16th International Conference on Pattern Recognition. IEEE, 2002. Vol. 4. P. 150-155. doi:10.1109/ icpr.2002.1047421

8. Fergus R., Perona P., Zisserman A. Object class recognition by unsupervised scale-invariant learning // Proceedings of Computer Society Conference on Computer Vision and Pattern Recognition. IEEE, 2003. Vol. 2. P. 256-264. doi:10.1109/ cvpr.2003.1211479

9. Harzallah H., Jurie F., Schmid C. Combining efficient object localization and image classification // 12th International Conference on Computer Vision. IEEE, 2009. P. 237-244. doi:10.1109/ iccv.2009.5459257

10. Kim S., Yoon K. J., Kweon I. S. Object recognition using a generalized robust invariant feature and Gestalt's law of proximity and similarity // Pattern Recognition. 2008. Vol. 41, No. 2. P. 726-741. doi:10.1016/j.patcog.2007.05.014

11. Kulkarni S. R., Harman G. Statistical learning theory: a tutorial // Wiley Interdisciplinary Reviews: Computational Statistics. 2011. Vol. 3, No. 6. P. 543-556. doi:10.1002/wics.179

12. Modeling and recognition of landmark image collections using iconic scene graphs / Li X. et al. // Computer Vision. ECCV, Springer Berlin Heidelberg, 2008. P. 427-440. doi:10.1007/ 978-3-540-88682-2 33

13. Achler O., Trivedi $\bar{M}$. Vehicle Wheel Detector using $2 \mathrm{D}$ Filter Banks, Accepted // International Conference on Intelligent Vehicles. 2004. doi:10.1109/ivs.2004.1336350
14. Viola P., Jones M. J., Snow D. Detecting Pedestrians Using Patterns of Motion and Appearance // International Journal of Computer Vision. 2005. Vol. 63, No. 2. P. 153-161. doi:10.1007/s11263-005-6644-8

15. Sun Z., Bebis G., Miller R. On-road vehicle detection using gab or filters and support vector machines // International Conference on Digital Signal Processing. 2002. Vol. 2. P. 1019-1022. doi:10.1109/icdsp.2002.1028263

16. Lymarenko Y., Tatievskyi D. Development of the computer mode of three dimensional surfaces reconstruction system // Technology audit and production reserves. 2017. Vol. 5, No. 2 (37) P. 11-16. doi:10.15587/2312-8372.2017.111233

17. Degtiareva A., Vezhnevec V. Preobrazovanie Hafa // Komp'iuternaia grafika i mul'timedia. 2003. No. 1 (1). URL: http:// ict.informika.ru/ft/002407/num1degt.pdf

18. Bradski G., Kaehler A. Learning OpenCV Computer Vision with OpenCV // Library. O'Reilly Media Publishers, 2008. URL: http://www.bogotobogo.com/cplusplus/files/OReilly\%20 Learning\%20OpenCV.pdf

\section{РАСПОЗНАВАНИЕ КОЛЕС С ПОМОЩЬЮ ЛАЗЕРА ДЛЯ ВЫЧИСЛЕНИЯ ДЕ中ОРМАЦИИ ШИН}

В ходе исследований реализован алгоритм распознавания луча лазера в области колеса транспортного средства, что, несомненно, имеет самостоятельную ценность. Получено минимизированное количество пикселей в ROI (область колеса) для последующего восстановления 3D-модели колес. При такой модели произведены вычисления коэффициентов деформации колес транспортного средства.

ключевые слова: детектор ребер Канне, дифференциальный оператор Собеля, компьютерное зрение, медианный фильтр, преобразования Хафа.

Lymarenko Yuliia, PhD, Associate Professor, Department of Computerized System Software, Zaporizhzhya State Engineering Academy, Ukraine, ORCID: http://orcid.org/0000-0002-1643-6939

Tatievskyi Dmitry, Postgraduate Student, Department of Compu terized System Software, Zaporizhzhya State Engineering Academy. Ukraine, e-mail: dtdissert@gmail.com, ORCID: http://orcid.org/ 0000-0002-7841-9560

\section{Gaidaichuk V., Kotenko K. Kedyk I. \\ DEVELOPMENT OF THEORETICAL AND EXPERIMENTAL DYNAMIC MONITORING OF LARGE-SCALE BUILDING STRUCTURE}

Встановлена доцільність використання динамічного моніторингу в системі контролю технічного стану будівельних споруд. Створена скінченно-елементна модель споруди, обгрунтовано $\dddot{\imath}$ використання в комплексній системі моніторингу споруди. Розроблено варіант автоматизованої системи експериментального динамічного моніторингу $і$ сформульовані умови ефективного його використання. Розрахунковим способом виявлені моніторингові точки споруди.

Ключові слова: Әинамічний моніторинг, частоти і форми власних коливань, скінченно-елементна модель.

\section{Introduction}

In recent years there has been a tendency to increase the number of accidents in the construction of industrial and civil infrastructure. So the collapse of the roof underwent the construction of Transvaal-Park in Russia (Moscow,
2004). Similar, the most famous accidents occurred at the exhibition center in the Polish city of Katowice (2006), in the skating rink in Bad Reichel (Germany, 2006), in the shopping center «Maxima» (Riga, Latvia 2013), in a sports complex of a factory of a medical glass in Poltava (Ukraine, 2016). 